\title{
Clinical evaluation of dry eyes in patients with rheumatoid arthritis
}

\author{
Sandeep. $K^{1}$, Phanindhara Reddy Yerramreddy ${ }^{2, *}$ \\ ${ }^{\mathbf{1}}$ Associate Professor, ${ }^{2}$ Consultant Ophthalmologist, Dept. of Ophthalmology, P K Das Institute of Medical Sciences, Palakkad, \\ Kerala, ${ }^{2}$ MRC Eye Hospital, Mysore, Karnataka, India
}

*Corresponding Author: Phanindhara Reddy Yerramreddy

Email: anu2bdoc@gmail.com

\begin{abstract}
Purpose: To detect dry eye and to associate it with rheumatoid factor and severity of disease in rheumatoid arthritis. Materials and Methods: Cross-sectional explorative study \& study period December 2013 to October 2015. Fifty nine eyes of 30 patients diagnosed as rheumatoid arthritis age > 18 years were included. Status of rheumatoid factor, severity of disease calculated with DAS28-ESR were noted and TBUT, Fluorescein staining and Schirmer's Test were done.

Results: Out of 59 eyes $42.4 \%$ had TBUT $<10$ seconds (mean $6.96 \pm 1.54$ seconds) and $57.6 \%$ had TBUT $\geq 10$ seconds (mean $17.97 \pm 3.60$ seconds), $37.3 \%$ had Schirmer's I $\leq 5 \mathrm{~mm}$ at 5 minutes (mean $3.4 \pm 1.05 \mathrm{~mm}$ ) and $62.7 \%$ had Schirmer's I $>5 \mathrm{~mm}$ (mean $18.7 \pm 6.8 \mathrm{~mm}$ ). $42.4 \%$ were diagnosed with dry eye. Out of 51 eyes with positive rheumatoid factor 24 had dry eye but 1 out of 8 eyes with negative rheumatoid factor had dry eye $(\mathrm{p}=0.066)$. Mean severity score of disease based on DAS28-ESR was 2.9 in dry eye and 4.1 in patients without dry eye.

Conclusion: Dry eye in rheumatoid Arthritis can be detected by simple tests and there is no statistically significant association between rheumatoid factor and dry eye. Dry eye is independent of severity of disease.
\end{abstract}

Keywords: Dry eye, Rhematoid arthritis.

\section{Introduction}

Rheumatoid arthritis is the most common autoimmune disease associated with dry eye syndrome ${ }^{14}$. RA is a chronic and multi systemic inflammatory autoimmune disease of unknown aetiology. It affects $1 \%$ of the general population, being three times more frequent in women than men. ${ }^{15,16}$

The inflammatory process can spread to other systems and organs causing extra-articular manifestations of RA which can affect equally men and women and can appear at any age.

Extra-articular manifestations of RA occur in about $40 \%$ of patients either in the beginning or during the course of their disease which increases morbidity and mortality.

The total number and severity of extra-articular symptoms varies with the duration and severity of the disease

Rheumatoid arthritis is a risk factor for dry eye in the Indian population. ${ }^{10}$ Dry eye is defined as a" multifactorial disease of the tears and ocular surface that results in symptoms of discomfort, visual disturbance and tear film instability with potential damage to the ocular surface. ${ }^{1}$ It is accompanied by increased osmolarity of the tear film and inflammation of the ocular surface".

Many patients suffer from ocular-related symptoms, such as stinging, burning, itching, light sensitivity, and blurry vision which limit the quality of life, as well as occupational

Productivity and severity of dry eye is independent of rheumatoid arthritis activity. ${ }^{12}$ Most common ocular manifestation with rheumatoid arthritis was secondary sjogren's syndrome ${ }^{13}$ other conditions include episcleritis, ${ }^{9}$ statistically significant association between the presence of dry eyes and association of RA duration more than 10 years has been proved.

Hence, this study is undertaken to evaluate rheumatoid arthritis patients for dry eyes and to correlate duration of RA with dry eyes.

\section{Aims and Objectives}

1. To evaluate for dry eyes in rheumatoid arthritis patients.

2. To correlate between dry eyes and duration of rheumatoid arthritis.

3. Association of rheumatoid factor with dry eyes.

\section{Materials and Methods}

Fifty nine eyes of 30 patients were enrolled in the study.

Study Design: It was an Cross-sectional explorative study.

Study Period: December 2013 to October 2015.

Source of Data: Patients attending outpatient department \& patients referred by Rheumatologist for dry eye evaluation at Mysore Race Club Eye Hospital, Mysore. Data regarding duration of rheumatoid arthritis, medications, serology of rheumatoid factor, total swollen joints, total tender jonts, erythrocyte sedimentation rate ${ }^{3}$ and visual analogue score of patient global health were noted from records. Dry eye symptoms obtained through questionnaire and detailed ocular examination done by slit lamp.

\section{Inclusion Criteria ${ }^{4}$}

1. Patients diagnosed with rheumatoid arthritis for a duration greater than 5 years. 


\section{Age greater than 18 years.}

\section{Exclusion Criteria}

1. Presence of other autoimmune systemic disorders like systemic lupus erythematosus etc.,

2. Patients with lid margin problems like Ectropion, Trichiasis etc.,

3. Patients with Acute Infective diseases of eye like conjunctivitis, keratitis etc.,

4. Patients on local/systemic medications known to cause dry eyes like Tricyclicantidepressants (Amitriptyline), Antihistamines (Chlorpheniramine maleate) etc.,

5. Patients who have undergone radiation therapy in head and neck region.

6. Patients with uncorrected refractive errors with symptoms related to dry eyes.

7. Patients who have undergone refractive surgeries, sac surgeries, pterygium surgeries, contact lens wearers.

Sample size calculated from formula: $\mathrm{Z}^{2} \mathrm{Pq} / \mathrm{d}^{2}$

$\mathrm{Z}=1.96$

$\mathrm{P}=$ proportion of prevalence

$\mathrm{Q}=1-\mathrm{P}$

$\mathrm{d}=0.05$ (margin of error)AS

Sampling Method: Purposive sampling

All the patients who are diagnosed as rheumatoid arthritis by Rheumatologist selected on basis of inclusion criteria were evaluated by taking demographic data such as age and sex. Following which detailed history of rheumatoid arthritis were taken including duration of RA, medications, values of erythrocyte sedimentation rate and rheumatoid factor are noted from records of patients. These findings were recorded on predesigned proforma.

\section{Discussion}

Age of patients in this study was between 35 to 67 years with mean age of $49.46 \pm 9.17$ years. In similar studies Piper et $\mathrm{al}^{6}$ reported mean age as $58.89 \pm 11.73$ years.

In this study 23 out of 7 patients $(76.7 \%)$ were females which is similar to other studies. Vignesh AP et ${ }^{5}$ al study on 196 patients reported 150 patients (77\%) were females and Piper et $\mathrm{al}^{6}$ study on 75 patients reported 59 patients $(78.7 \%)$ were females. This female preponderance is due to the fact females are affected more commonly than males in rheumatoid arthritis.

In this study out of 30 patients 21 were in the range of 5-10 years, 5 were in the range of 11-15 years, 3 were in the range of 16-20 years and 1 in the range of 21-25 years of duration of illness and the mean was $9.5 \pm 5.32$ years. Polanska $\mathrm{V}$ et $\mathrm{al}^{2}$ study reported duration of rheumatoid arthritis was $12.3 \pm 11.0$ years. Vignesh AP et $\mathrm{al}^{5}$ study reported mean duration of RA in patients with ocular manifestations was $5.4 \pm 2.7$ years and in patients without ocular manifestations as $2.1 \pm 1.6$ years. This difference in mean duration of RA with other was because of inclusion of RA patients with illness greater than or equal to 5 years from the date of diagnosis.

In this study 26 out of $30(86.7 \%)$ patients are positive for rheumatoid factor. Reddy et $\mathrm{al}^{7}$ study reported out of 100 patients $45(45 \%)$ were positive and $55(55 \%)$ were negative for rheumatoid factor and presence of rheumatoid factor does not correlate with the prevalence of ocular manifestations. Polanska et $\mathrm{al}^{2}$ study also reported no statistical significance between rheumatoid factor presence and dry eye syndrome. Although in this study majority of patients are rheumatoid factor there is no statistical significance between them which is similar to previous studies.

Mean severity of rheumatoid arthritis which was based on DAS28-ESR ${ }^{3}$ was 2.9 in dry eye patients (14 patients) and 4.1 in no dry eye patients (16 patients). There was no relationship between severity of RA and dry eye in this study, Zahra Zakeri et $\mathrm{al}^{8}$ and Polanska et $\mathrm{al}^{2}$ study reported no statistically significant correlation between severity of rheumatoid arthritis and dry eye syndrome.

In this study out of 59 eyes $8(13.5 \%)$ were noted with meibomian gland disease, $16(27.1 \%)$ were noted with congestion, $4(6.8 \%)$ were noted with discharge and $8(13.5 \%)$ were noted with filamentary keratitis. Vignesh AP et ${ }^{5}$ al study reported filamentary keratitis in 6 patients $(3 \%)$.

In this study $42.4 \%$ were noted to have tear film breakup time $<10$ seconds and considered to be having dry eye with mean TBUT $6.96 \pm 1.54$ seconds and the remaining $57.6 \%$ were noted to have TBUT $>10$ seconds with mean TBUT 17.97 \pm 3.60 seconds. Polansk $\mathrm{V}$ et $^{2}$ al study reported out of 100 patients TBUT positive $84 \%$ of patients. In this study out of $37.3 \%$ were noted to have Schirmer's $\mathrm{I} \leq 5$ millimeter $(\mathrm{mm})$ and considered to be having dry eye with mean value of wetting $3.4 \pm 1.05 \mathrm{~mm}$ and the remaining $62.7 \%$ were noted to have Schirmer's I $>5 \mathrm{~mm}$ with mean value of wetting $18.7 \pm 6.8 \mathrm{~mm}$. Polansk $\mathrm{V}$ et $\mathrm{al}^{2}$ study reported $67 \%$ were positive for Schirmer I. Vignesh AP et al ${ }^{5}$ study reported mean value of Schirmer's I $4.2 \pm 0.7$ $\mathrm{mm}$ in patients with ocular manifestations which is similar to present study.

In this present study $33.9 \%$ had superficial punctate keratitis with fluorescein staining. Polanska V $\mathrm{et}^{2}$ al study corneal fluorescein staining appeared in $18 \%$. In this study $42.4 \%$ were diagnosed with dry eye based on positive value for any one of diagnostic tests. Piper et $\mathrm{al}^{6}$ study reported dry eye in $70.7 \%$ participants based on Schirmer's test. Polanska $\mathrm{V}$ et $\mathrm{al}^{2}$ study reported dry eye in $74 \%$ patients. Vignesh AP et $\mathrm{al}^{5}$ study reported dry eye in $28 \%$ patients.

Vignesh AP et $\mathrm{al}^{5}$ study reported significant association between the duration of the disease and ocular manifestations. In this study majority of dry eyes $16(64 \%)$ out of 25 were with in the range of 5-10 years, $3(12 \%)$ were with in the range of 11-15 years, 4 
$(16 \%)$ were in the range of $16-20$ years and $2(8 \%)$ were with in the range of 21-25 years of duration of RA. As there is no equal distribution of patients in all groups statistical significance cannot be established. $3(12 \%)$ out of 25 dry eyes are males and remaining $88 \%$ were females.

\section{Results and Observations}

Table 1: Gender distribution in study population

\begin{tabular}{|l|c|c|}
\hline \multicolumn{1}{|c|}{ Gender } & No of Patients & Percentage (\%) \\
\hline Male & 7 & 23.3 \\
\hline Female & 23 & 76.7 \\
\hline
\end{tabular}

In this study $23(76.7 \%)$ were female patients indicating Female preponderance.

\section{Graph 1: Symptoms in study population}

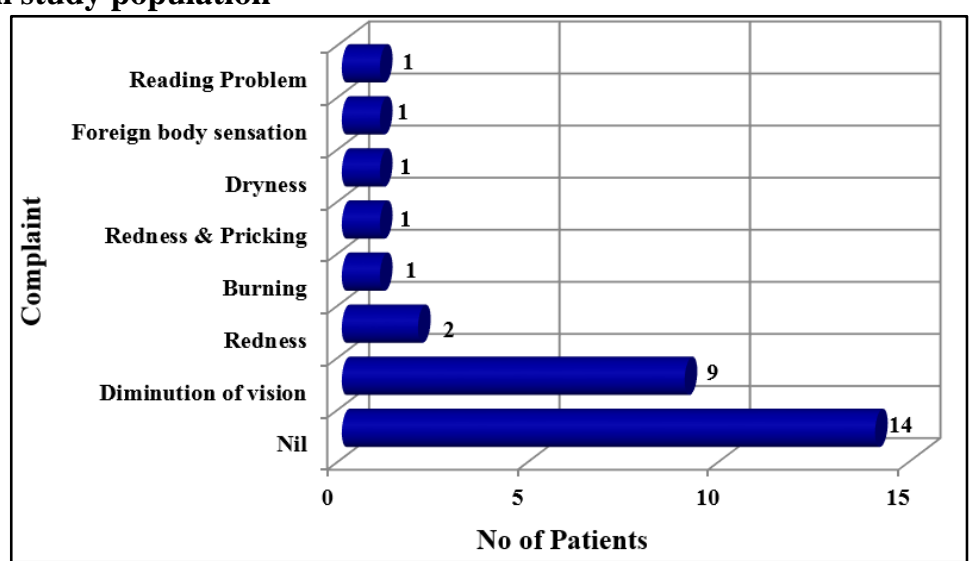

In this present study 14 out of 30 patients (46.7) were asymptomatic. Showing Schirmer's I (mm) in study population.

\begin{tabular}{|l|c|c|}
\hline \multicolumn{1}{|c|}{ Schirmer'sI (mm) } & No of Eyes & \% \\
\hline$\leq 5$ & 22 & 37.3 \\
\hline$>5$ & 37 & 62.7 \\
\hline Total & 59 & 100.0 \\
\hline
\end{tabular}

In this study 22 out of 59 eyes are noted with Schirmer's $\mathrm{I} \leq 5 \mathrm{~mm}$ at 5 minutes. Showing result in study population

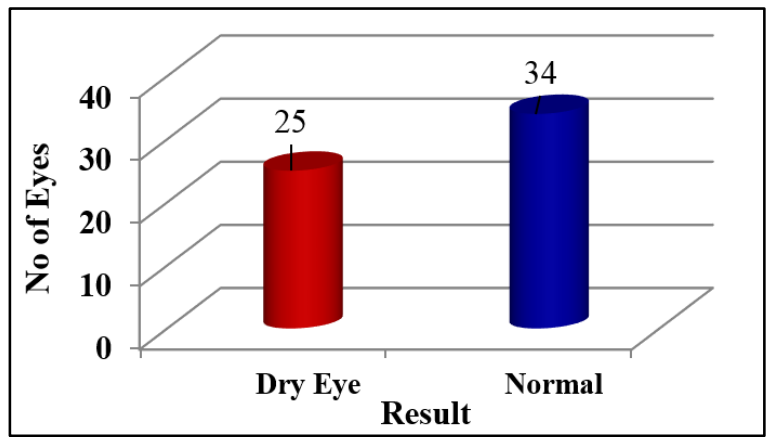

In this study 25 out of 59 eyes are diagnosed with dry eye.

\section{Conclusions}

Dry eye, a common extra articular manifestation in rheumatoid arthritis can be detected by simple tests like tear film breakup time and Schirmer's test ${ }^{11}$ and there was no association between rheumatoid factor and presence of dry eye.

\section{References}

1. The definition and classification of dry eye disease: Report of the Definition and Classification Subcommittee of the International Dry Eye Worksshop (2007) Ocular Surface. 5:75-92.

2. Polanska V, Sery O, Fojtík Z, Hlinomazova Z. The presence of dry eye syndrome and corneal complications in patients with rheumatoid arthritis and its association with -174 gene polymorphism for interleukin 6. Cesk Slov Oftalmol. 2008;64:77-80.

3. Eisuke Inoue, Hisashi Yamanaka, Masako Hara, Taisuke Tomatsu, Naoyuki Kamatani. Comparison of Disease Activity Score (DAS)28- erythrocyte sedimentation rate andDAS28-C-reactive protein threshold values. Ann Rheum Dis. 2007;66:407-09.

4. Methodologies to diagnose and monitor dry eye disease: report of the Diagnostic Methodology Subcommittee of the International Dry Eye Work Shop. 2007;5(2):108152.

5. Vignesh, Srinivasan. Ocular manifestations of rheumatoid arthritis and their correlation with anti-cyclic citrullinated peptide antibodies. Clinical Ophthalmology. 2015;9:39397.

6. Piper H, Douglas KM, Treharne GJ, Mitton DL, Haider S, Kitas GD. Prevalence and predictors of ocular manifestations of RA: is there a need for routine screening? Musculoskeletal care. 2007;5(2):102-17.

7. Reddy SC, Gupta SD, Jain IS, Deodhar SD. Ocular manifestations of rheumatoid Arthritis. Indian J Ophthalmol. 1977;25(3):20-26.

8. Zakeri Z, Parsa M, Zanjani H, Ansarimoghaddam A, Sandoughi M, Aminifard M. Relationship Between 
Severity of RA and Dry Eye. Health Scope.

9. Brun JG, Madland T, Jonsson R. A prospective study of sicca symptoms in patients with rheumatoid arthritis. Arthritis and Rheumatism. 2003;49(2):187-92.

10. Punjabi OS, Adyanthaya RS, Mhatre AD, Jehangir RP. Ophthalmic epidemiology. 2006;13:379-84.

11. Kosrirukvongs $P$, Ngowyutagon $P$, Pusuwan $P$, Koolvisoot A, Nilganuwong S. Journal of the Medical Association of Thailand. 2012;95Suppl 4:S61-9.

12. Fujita M, Igarashi T, Kurai T, Sakane M, Yoshino S, Takahashi H. American Journal of Ophthalmology. 2005; 140:808-13.

13. Kosrirukvongs $\mathrm{P}$, Ngowyutagon $\mathrm{P}$, Pusuwan $\mathrm{P}$, Koolvisoot A, Nilganuwong S. Journal of the Medical Association of Thailand. 2012;95Supp14:S61-9.

14. Shaw C, Banik S, Islam MN, Biswas MC, Biswas G, Biswas S. Journal of Indian Medical Association. 2003;101(9):537-8.

15. Ronald $\mathrm{F}$ van villenhoen. BMC Medicine. 2009;7:12
2012;1(4):186-188.

16. Talal N. Sjögren's syndrome: historical overview and clinical spectrum of disease. Rheum Dis Clin North Am. 1992,18:507-515.

How to cite this article: Sandeep. K, Yerramreddy P. R. Clinical evaluation of dry eyes in patients with rheumatoid arthritis. Indian J Clin Exp Ophthalmol. 2018;4(4):435438 . 